\title{
Histamine-3 Receptor Inverse Agonists for the Treatment of Obesity: Validation of the Target and Identification of Novel Series
}

\author{
Pascale David Pierson, Christian Freichel, Silvia Gatti-Mac Arthur, Cornelia Hertel, \\ Jörg Huwyler, Peter Mohr, Toshito Nakagawa, Matthias Nettekoven, Jean-Marc Plancher $\S^{\star}$, \\ Susanne Raab, Hans Richter, Olivier Roche, Rosa María Rodríguez Sarmiento, Monique Schmitt, \\ Franz Schuler, Tadakatsu Takahashi, Sven Taylor, Christoph Ullmer, and Ruby Wiegand \\ §SCS-Mettler Toledo Award Winner (Oral Presentation)
}

\begin{abstract}
Obesity is a major risk factor for the development of conditions such as hypertension, hyperglycemia, dyslipidemia, coronary artery disease and cancer. Several pieces of evidence, including data in primates, have demonstrated the beneficial effects of histamine-3 receptor $\left(\mathrm{H}_{3} \mathrm{R}\right)$ inverse agonists in the regulation of food intake and body weight. A pharmacophore model based on selected published $\mathrm{H}_{3} \mathrm{R}$ ligands and validated by previous investigations, was used to identify the 5-oxy-2-carboxamide-indole core as a novel series of $\mathrm{H}_{3} \mathrm{R}$ inverse agonists. Extensive structure-activity relationship (SAR) investigations were rewarded by the identification of several compounds reversing $(R)-\alpha$-methyl-histamine-induced water intake increase and reducing food intake/ body weight in rodent models of obesity. Among those compounds, (4,4-difluoro-piperidin-1-yl)-[1-isopropyl-5(1-isopropyl-piperidin-4-yloxy)-1H-indol-2-yl]-methanone, selected as a lead compound, was exhibiting a promising profile, including excellent pharmacokinetic properties, good in vitro safety profile and high efficacy in a chronic rodent model of obesity.
\end{abstract}

Keywords: hERG · Histamine-3 receptor · Inverse agonist · Obesity · Pharmacophore model

\section{Introduction}

The histamine receptor family, comprising the four subtypes $1-4,[1]$ has already received considerable attention, and led to several blockbusters in the inflammation and gastric secretion fields. ${ }^{[2]}$ Within this family, the histamine- 3 receptor $\left(\mathrm{H}_{3} \mathrm{R}\right)$ acts both as an autoreceptor, controlling the synthesis and release of histamine, and also as a heteroreceptor, controlling other crucial neurotransmitters (e.g. acetylcholine, norephedrine, serotonin, dopamine).[3]

As a consequence of this rich pharmacology, three distinct therapeutic areas can potentially be envisaged: central nervous system (CNS) disorders (e.g. Alzheimer, schizophrenia, anxiety, cognitive deficit),
${ }^{\star}$ Correspondence: Dr. J.-M. Plancher

F. Hoffmann-La Roche Ltd

Pharmaceuticals Division

B092/4.18C

$\mathrm{CH}-4070$ Basel

Tel.: + 41616886725

Fax: +416168 88367

E-mail: jean-marc.plancher@roche.com sleep disorders and metabolic disorders. ${ }^{[4]}$ Among the latter, we decided to concentrate on obesity, a dramatically increasing burden with tremendous needs for novel and efficient therapies.

$\mathrm{H}_{3} \mathrm{R}$ is highly constitutively active; therefore, most of the antagonists should be properly classified as inverse agonists. In term of mechanism, $\mathrm{H}_{3} \mathrm{R}$ inverse agonists/antagonists suppress food intake via increased histamine release and consequently, increased activation of postsynaptic histamine-1 receptor $\left(H_{1} R\right)$. This $H_{1} R$ activation is restricted to the CNS, where the $\mathrm{H}_{3} \mathrm{R}$ is mainly expressed.

Indeed, in recent years, some potent and selective $\mathrm{H}_{3} \mathrm{R}$ antagonists/inverse agonists have demonstrated efficacy in several models of obesity, including in primates. However, some of these compounds also showed clear limitations mainly in terms of safety (e.g. hERG affinity/cardiovascular liabilities, genotoxicity, CNS side effects).[5]

\section{Pharmacophore Model}

characterized by a basic $\mathrm{sp}_{3}$ nitrogen (yellow circle in Fig. 1), acting as the main anchor, most probably through a salt bridge formation with Asp3.32. At a distance of 4-5 $\AA$, an electron-rich entity, typically an ether or a carbonyl oxygen (red circle in Fig. 1) is often observed across different chemical series. Optionally, a second basic nitrogen atom can be present at around $10-11 \AA$ A from the first one, most probably interacting with Glu5.46. However, some concerns about risks for brain accumulation and phospholipidosis prompted us to avoid this second basic nitrogen. In contrast, we postulated the importance of a second electron rich entity, probably interacting with Thr6.52. Interestingly, this threonine is only present in the $\mathrm{H}_{3} \mathrm{R}$.

Compared to other scaffolds initially investigated, ${ }^{[6-8]}$ the indole series appeared to have the widest potential, including the option of easy access to a third exit vector on the indole nitrogen - so far poorly explored - and an excellent chemical tractability.

\section{Early SAR and Chemistry}

The availability of many published structures of potent $\mathrm{H}_{3} \mathrm{R}$ ligands has facilitated the construction of an accurate pharmacophore model.[6,7] This model is
Capitalizing on our previous investigations, ${ }^{[7,8]}$ the identification of $\mathrm{H}_{3} \mathrm{R}$ inverse agonists proved to be straightforward by 


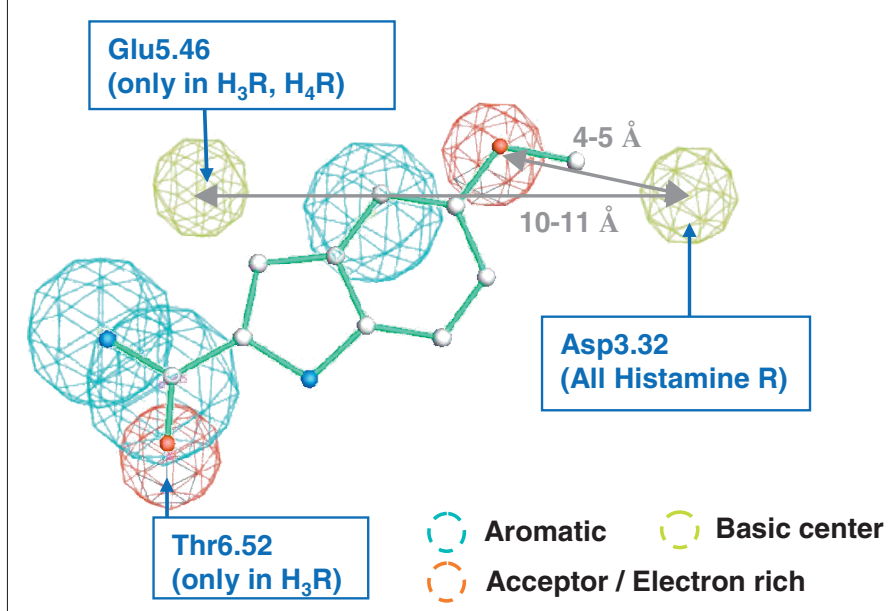

Fig. 1. 5-Oxy-2-carboxamide indole docked into the $\mathrm{H}_{3} R$ pharmacophore model.

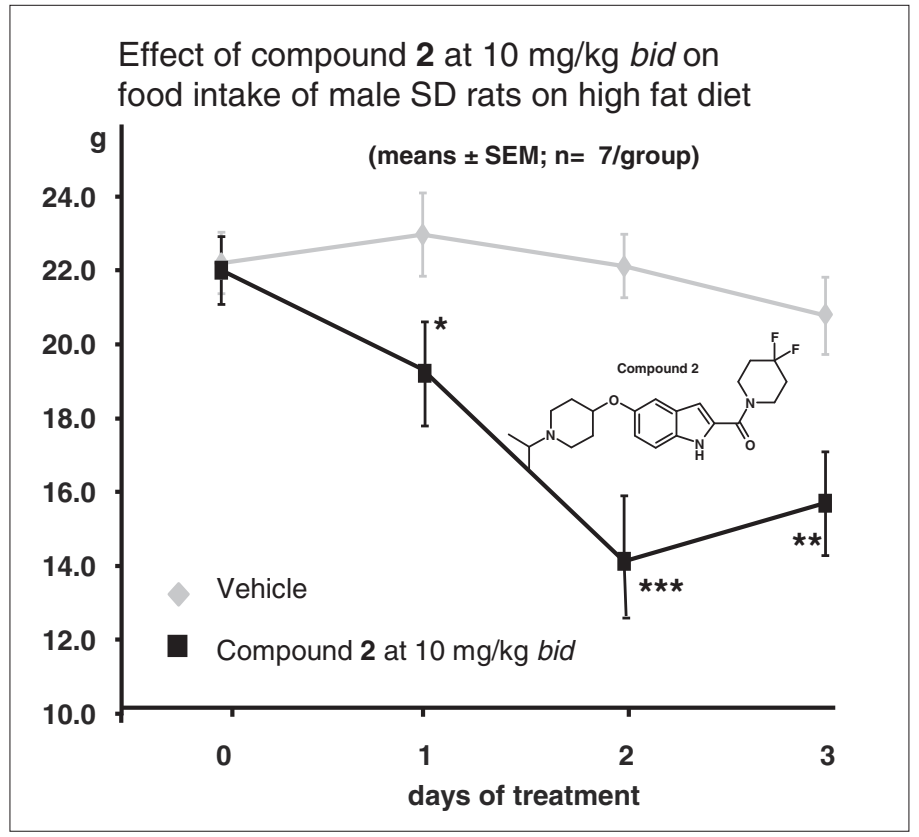

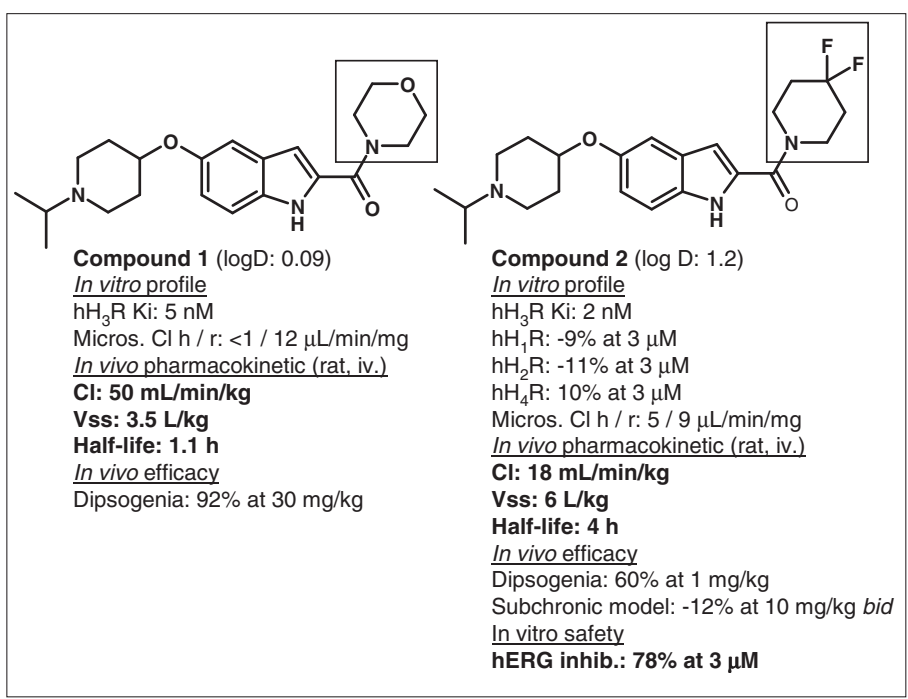

Fig. 2. Selected examples for the influence of the amide substituent on the metabolic stability.

Fig. 3. Efficacy of compound 2 in a subchronic model of obesity at $10 \mathrm{mg} / \mathrm{kg}$ bid. combining a 1-isopropyl-piperidin-4-oxy substituent on the 5-position of the indole with a cyclic amide on the 2-position. Being potent $\left(\mathrm{hH}_{3} \mathrm{R} \mathrm{Ki}=5 \mathrm{nM}\right)$ and metabolically stable in microsomal preparation ( $\operatorname{micros} . \mathrm{Cl}$ human $/ \mathrm{rat}=<1 / 12 \mu \mathrm{l} / \mathrm{min} / \mathrm{mg}$ ), compound 1 was an excellent candidate for the first line in vivo screening experiment: the dipsogenia assay. ${ }^{[9]}$ This experiment is based on an antagonist/inverse agonist reversion of the water-intake induced by the $\mathrm{H}_{3} \mathrm{R}$ selective agonist $(R)$ - $\alpha$-methylhistamine (RAMH) in rat.

In this in vivo functional assay, compound 1 reversed the RAMH-induced water intake by $92 \%$ at $30 \mathrm{mg} / \mathrm{kg}$. Therefore, we decided to further profile this promising compound in a disease-relevant model. Compound 1 was applied at a dose of 30 $\mathrm{mg} / \mathrm{kg}$ bid (twice daily) over three days to Sprague Dawley (SD) rats fed with a high fat diet (HFD, $42 \%$ of energy intake as fat), and their body weight was recorded. To our disappointment, compound $\mathbf{1}$ did not show any significant effect in this sub-chronic model. Although the compound was able to permeate the CNS (brain to plasma ratio $=0.3$ ), pharmacokinetics disappointingly revealed a fast metabolism $(\mathrm{Cl}$ tot. $=$ $50 \mathrm{ml} / \mathrm{min} / \mathrm{kg})$ and a short half-life $\left(\mathrm{t}_{1 / 2}=1\right.$ h). We hypothesized that a longer half-life might be required to cover the whole active period of the animal (i.e. $12 \mathrm{~h}$ during the dark phase) and started searching for compounds with such a property.

The replacement of the morpholine by the more lipophilic piperidine, shielded by two fluorine atoms, led simultaneously to a reduction of the in vivo clearance and an enlarged volume of distribution, both leading towards an improved half-life. Compound $\mathbf{2}$ exhibited a promising half-life $\left(\mathrm{t}_{1 / 2}=4 \mathrm{~h}\right)$ while maintaining an excellent affinity $\left(\mathrm{hH}_{3} \mathrm{R} \mathrm{Ki}=2 \mathrm{nM}\right)$. It was moreover extremely selective over the three other histamine isoforms (Fig. 2).

To our delight, this profile translated into a robust efficacy in the sub-chronic model of obesity, in line with our hypothesis on the critical importance of the halflife (Fig. 3).

However, compound $\mathbf{2}$ demonstrated some inhibitory potential for the human ether-a-go-go related gene (hERG). hERG inhibition is considered to be an in vitro predictor of potential cardiovascular liabilities. Taking into account the late failure of some competitors' compounds because of cardiovascular-related issues, ${ }^{[5]}$ the $78 \%$ inhibition value of the hERG channel at 10 $\mu \mathrm{M}$ was therefore judged suboptimal (Fig. 2).

As far as hERG inhibition is concerned, a basic nitrogen is often suspected as the usual culprit, although definitely not the only one. ${ }^{[10]}$

Therefore the relationship between pKa, $\mathrm{hH}_{3} \mathrm{R}$ affinity and hERG inhibition was studied by varying the needle at the 5-position. Compound 3, an analog of the original compound $\mathbf{1}$ decorated with an additional N-2,2,2-trifluoroethyl group side-chain, exhibited a pKa of 9.7. In the same series, replacement of the $\mathrm{N}$-isopropyl by a $\mathrm{N}$-cyclopropyl reduced the $\mathrm{pKa}$ by about $2 \log$ units (compound 4: $\mathrm{pKa}=$ 7.5) without a major change on the $\mathrm{hH}_{3} \mathrm{R}$ affinity. On the other hand, using the linear propyloxy linker, it was demonstrated that the phenolic ether in compound $\mathbf{5}$ could be advantageously replaced by a carbonyl group (compound 6). We decided to combine both modifications - a low $\mathrm{pKa}$ and a carbonyl group - into a unique needle. As a result, the carbonylpiperazine 7 featured a very low $\mathrm{pKa}$ value $(\mathrm{pKa}=6.8)$ while keeping an excellent binding affinity $\left(\mathrm{hH}_{3} \mathrm{R}\right.$ 


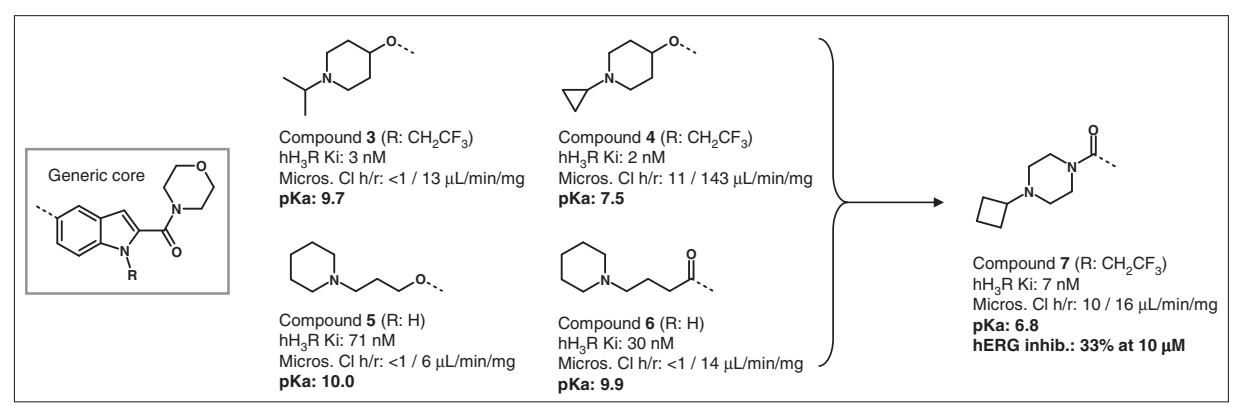

Fig. 4. Selected examples exploring the side chain basicity.

\section{ROSARA: Roche Automatic SAR Analyser} - Intuitive and user friendly proprietary tool - Democratizing the use of partial least square analysis - Designed to study potential correlation between a defined compound property (i.e. hERG inhibition) and numerous descriptors (both measured or calculated values).

Application:

-hERG $\mathrm{pIC}_{50}=\mathrm{f}($ Membrane fraction in PAMPA, $\log \mathrm{D})$ -Regression coefficient: 0.736

-Prediction used to prioritize compound profiling

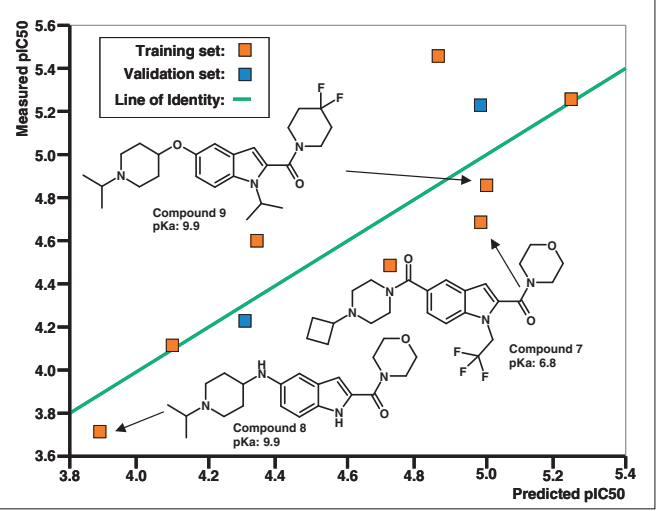

Fig. 5. Correlation of experimental vs. calculated hERG plC $_{50}$, using Roche Automatic SAR Analyser (ROSARA).

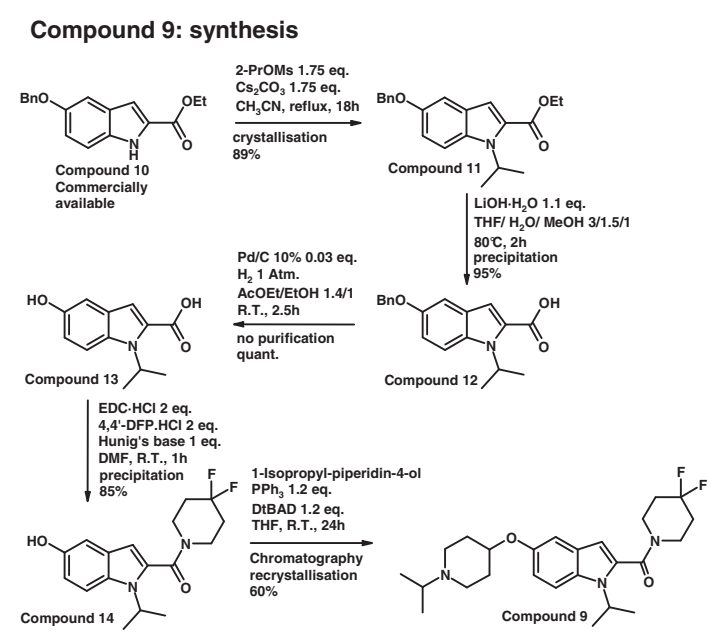

Fig. 6. Profile and chemical synthesis of compound $\mathbf{9}$.

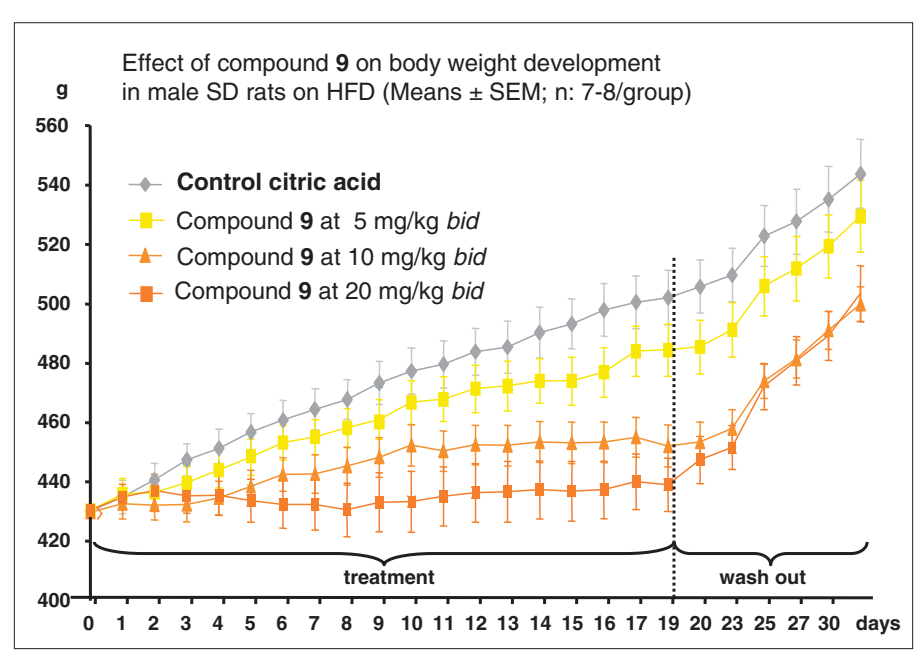

Fig. 7. Chronic application of compound 9 at 5 (yellow), 10 (orange) and 20 (red) $\mathrm{mg} / \mathrm{kg}$ bid in a Diet-Induced Obesity rat model.
$\mathrm{Ki}=7 \mathrm{nM})$. The hERG inhibition was also reduced (Fig. 4). Although, thanks to this exercise it became clear that $\mathrm{H}_{3} \mathrm{R}$ affinity was independent of the basicity within a broad pKa range (ca. 6.8-10.0), the relationship between $\mathrm{pKa}$ and hERG inhibition remained elusive.

In order to gain a better understanding, we have used ROSARA, the Roche Automatic SAR Analyser. [11] ROSARA is an intuitive and user friendly proprietary tool which democratizes the use of partial least square analysis. It is designed to allow a fast study of the putative correlations between a defined compound property (in this case: hERG inhibition, converted to $\left.\mathrm{pIC}_{50}\right)$ and numerical descriptors. These descriptors may be both measured (e.g. LYSA ${ }^{[12]}$ solubility, $\log \mathrm{D}, \mathrm{hH}_{3} \mathrm{R} \mathrm{Ki}, \mathrm{pKa}$, etc.) or calculated (e.g. clogP, PSA, etc.). In our case, ROSARA was able to generate a valuable hERG inhibition model (regression coefficient $=0.736$ ) by selecting only two in vitro descriptors: the percentage of membrane-bound compound in the Parallel Artificial Membrane Permeation Assay (PAMPA) ${ }^{[13]}$ and the $\log \mathrm{D}$ value (measured lipophilicity at $\mathrm{pH}=7.4$ ). As some small molecule hERG inhibitors are assumed to interact with this channel through the membrane section, this correlation did indeed make sense. Interestingly, although the $\mathrm{pKa}$ spanned over more than three log units in the training set, no correlation with $\mathrm{hERG}$ affinity was observed. The model has been validated with two new compounds from the same series (blue squares, Fig. 5).

The independence of $\mathrm{pKa}$ and $\mathrm{hERG}$ inhibition encouraged us to reinvestigate compounds having rather strong basicity ( $\mathrm{pKa}=9-10)$. Among them, compound 9 (Fig. 6) attracted our attention by its striking combination of a high $\mathrm{H}_{3} \mathrm{R}$ binding affinity $\left(\mathrm{hH}_{3} \mathrm{R} \mathrm{Ki}=7 \mathrm{nM}\right)$, low clearance in vivo (rat $\mathrm{Cl}$ tot. $=10 \mathrm{ml} \cdot \mathrm{min}^{-1} \cdot \mathrm{kg}^{-1}$ ), extended half life $\left(\mathrm{t}_{1 / 2}=11 \mathrm{~h}\right.$ in rat), rather low hERG inhibition ( $42 \%$ hERG inhibition at $10 \mu \mathrm{M})$ and, eventually, excellent performance in the 3-day obesity model $(-17 \%$ reduction of food intake at $10 \mathrm{mg} / \mathrm{kg}$ bid. compared to control).

The synthesis of compound 9 was straightforward: commercially available 5-benzyloxy-1H-indole-2-carboxylic acid ethyl ester $\mathbf{1 0}$ was $\mathrm{N}$-alkylated with isopropyl methane sulfonate. Both the acidic and the phenolic functionalities were liberated by saponification with lithium hydroxide and hydrogenolysis, respectively, followed by an amine coupling reaction. The ether was obtained by applying a Mitsunobu reaction. This end-game reaction required extensive optimization in order to minimize the elimination of the activated alcohol as a side-reaction. The overall yield was satisfactory (43\% over five steps). 
Applied in a chronic model of obesity (DIO model in male SD rats) over 17 days, compound 9 led to an impressive and dosedependent slower progression of body weight gain in all groups $(-4,-10,-13 \%$ respectively), statistically significant for the 10 and $20 \mathrm{mg} / \mathrm{kg}$ groups (Fig. 7).

\section{Conclusion}

The 5-indole-2-carboxamide-indole scaffold was identified as a valid chemistry entry point by the use of a pharmacophore model. A series of derivatives was identified as novel class of $\mathrm{H}_{3} \mathrm{R}$ inverse agonists. [14] After SAR development, extensive multidimensional optimization, and careful evaluation of the underlying drivers for the $\mathrm{H}_{3} \mathrm{R}$ binding affinity and hERG inhibition, compound 9 proved to combine suitable overall characteristics for advancement. In the indirect acute pharmacodynamic dipsogenia model, compound 9 reversed the water intake induced by the $\mathrm{H}_{3} \mathrm{R}$ selective agonist RAMH. Furthermore, in a 17-day Diet-Induced Obesity (DIO) rat model, compound 9 demonstrated a robust and dose dependant reduction in body weight gain. On the basis of its efficacy, metabolic stability and safety profile, compound 9 was selected for further evaluation of its potential for the treatment of obesity.

\section{Acknowledgment}

Authors wish to thank Dr. Holger Fischer for his help in the use of Roche Structure Activity Relationship Analyser (ROSARA).

Received: December 19, 2008
[1] M. E. Parsons, C. R. Ganellin, Br. J. Pharmacol. 2006, 147 , S127.

[2] a) S. J. Hill, C. R. Ganellin, H. Timmerman, J. C. Schwartz, N. P. Shankley, J. M. Young, W. Schunack, R. Levi, H. L. Haas, Pharmacol. Rev. 1997, 49, 253; b) S. J. Offord, Clin. Pharmacol. Ther. 2002, 71, Abst WPIII-27 P83; c) M. Harada, M. Terai, H. Maeno, Biochem. Pharmacol. 1983, 32, 1635.

[3] a) J.-M. Arrang, M. Garbarg, J.-C. Schwartz, Nature 1983, 302, 832; b) R. Leurs, P. Blandina, C. Tedford, H. Timmerman, Trends Pharmacol. Sci. 1998, 19, 177; c) R. Leurs, H. Timmerman, in 'The Histamine H3-Receptor: A Target for New Drugs', Ed. Elsevier, Amsterdam, 1998; d) H. Stark, J.-M. Arrang, X. Ligneau, M. Garbarg, C. R. Ganellin, J. C. Schwartz, W. Schunack, in 'The Histamine H3-receptor and its Ligands in Progress in Medicinal Chemistry', Ed. Elsevier, Amsterdam, 2001

[4] a) T. A. Esbenshade, G. B. Fox, M. D. Cowart, Mol. Interventions 2006, 6, 77; b) T. A. Esbenshade, K. E. Browman, R. S. Bitner, M. Strakhova, M. D. Cowart, J. D. Brioni, Brit. J. Pharmacol. 2008, 1.

[5] A. A. Hancock, Bio. Pharm. 2006, 71, 1103.

[6] O. Roche, R. M. Rodriguez Sarmiento, Bio. Med. Chem. Lett. 2007, 17, 3670.

[7] O. Roche, M. Nettekoven, W. Vifian, R. M. Rodriguez Sarmiento, Bio. Med. Chem. Lett. 2008, 18, 4377.

[8] M. Nettekoven, J.-M. Plancher, H. Richter, O. Roche, R. M Rodriguez Sarmiento, S. Taylor, Bio. Med. Chem. Lett. in press.

[9] a) G. B. Fox, J. B. Pan, T. A. Esbenshade, R. S. Bitner, A. L. Nikkel, T. Miller, C. H. Kang, Y. L. Bennani, L. A. Black, R. Faghih, A. A. Hancock, M. W. Decker, Pharm. Bio. \& Behav. 2002, 72, 741 .

(b) X. Ligneau, J.-S. Lin, G. Vanni-Mercier, M. Jouvet, J. L. Muir, C. R. Ganellin, H. Stark, S. Elz, W. Schunack, J.-C. Schwartz, J. Pharm. Exp. Ther. 1998, 287, 658 .

[10] a) L. Jia, H. Sun, Bio. Med. Chem. 2008, 16, 6252; b) E. Raschi, V. Vasina, E. Poluzzi, F. De Ponti, Pharmacol. Res. 2008, 57, 181; c) M. J. Waring, C. Johnstone, Bio. Med. Chem. Lett. 2007, 17, 1759; d) A. M. Aronov, J. Med. Chem. 2006, $49,6917$.
[11] H. Fischer, M. Kansy, PCT Int. Appl. US 2007027632 A1, 2007.

[12] LYophilisation Solubility Assay (LYSA): solubility was measured from lyophilized DMSO stock solutions spectrophotometrically at $\mathrm{pH}=6.5$ in a $0.05 \mathrm{M}$ phosphate buffer.

[13] M. Kansy, F. Senner, K. Gubernator, J. Med. Chem. 1998, 41, 1007.

[14] a) M. Nettekoven, J.-M. Plancher, H. Richter, O. Roche, S. Taylor, PCT Int. Appl. WO 2007115938A1, 2007; b) M. Nettekoven, J.-M. Plancher, O. Roche, T. Takahashi, S. Taylor, PCT Int. Appl. WO2007080140, 2007; c) M. Nettekoven, J.-M. Plancher, H. Richter, O. Roche, S. Taylor, U.S. Pat. Appl. Publ. US 2007123525 A1, 2007; d) M. Nettekoven, J.-M. Plancher, H. Richter, O. Roche, R. M. Rodriguez Sarmiento, S. Taylor, U.S. Pat. Appl. Publ. US 2007123526 A1, 2007; e) M. Nettekoven, J.-M. Plancher, H. Richter, O. Roche, V. Runtz-Schmitt, S. Taylor, U.S. Pat. Appl. Publ. US 2007123515 A1, 2007; f) M. H. Nettekoven, J.-M. Plancher, O. Roche, R. M. Rodriguez-Sarmiento, U.S. Pat. Appl. Publ. US 2006160855 A1, 2006. 